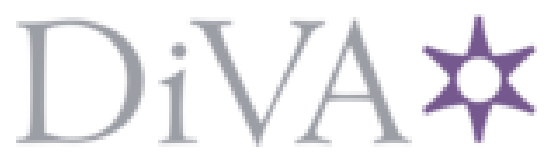

http://www.diva-portal.org

\title{
Postprint
}

This is the accepted version of a paper published in Journal of Marriage and Family. This paper has been peer-reviewed but does not include the final publisher proof-corrections or journal pagination.

Citation for the original published paper (version of record):

Connidis, I A., Borell, K., Ghazanfareeon Karlsson, S. (2017)

Ambivalence and Living Apart Together in Later Life: A Critical Research Proposal.

Journal of Marriage and Family, 79(5): 1404-1418

https://doi.org/10.1111/jomf.12417

Access to the published version may require subscription.

N.B. When citing this work, cite the original published paper.

Permanent link to this version:

http://urn.kb.se/resolve?urn=urn:nbn:se:hj:diva-36741 
INGRID ARNET CONNIDIS Western University

KLAS BoRELL Jönköping University*

Sofie Ghazanfareeon Karlsson Mid Sweden University**

\section{Ambivalence and Living Apart Together in Later Life: A Critical Research Proposal}

\begin{abstract}
Most unattached older persons who would like an intimate partnership do not want to remarry or be in a marriage-like relationship. A growing trend is to live apart together (LAT) in an ongoing intimate relationship that does not include a common home. We address the debate about whether LAT constitutes a new form of intimate relationship in a critical assessment of research on LAT relationships that applies ambivalence and concepts from the life course perspective. We conclude that among older but not younger adults, LAT relationships are generally a stable alternative to living with a partner, negotiated in the context of current social institutions and arrangements. We propose research questions that address later life living apart together as an innovative alternative intimate relationship. We encourage comparative work on the unique challenges of later life living apart together, their implications for other family ties, and their connection to social and cultural arrangements.
\end{abstract}

\footnotetext{
Department of Sociology, Western University, 1151 Richmond St., London, Ontario, Canada, N6A 5C2 (connidis@uwo.ca).

*Department of Social Work, Jönköping University, Gjuterigatan 5 Jönköping, Sweden.

${ }^{* *}$ Department of Social Work, Mid Sweden University,
Kunskapens väg 8 Österund, Sweden.
}

Key Words: aging, ambivalence, dating, family dynamics, gender, intimate relationships.
The intimate relationships of older persons in the Western world are characterized by continuity and change. Marriage still dominates, and, as more individuals live longer and healthier lives, many marriages survive well into old age. Nevertheless, notable changes have occurred. In the past, older people were generally affected indirectly by contemporary shifts in intimate ties, for example, by their adult children's divorces (Cherlin \& Furstenberg, 1986; Creasey, 1993). Now, an increasing number of older persons, especially the "young old" (65 to 74 years of age) are taking an active role in these processes (Connidis, 2010). The young old of today were teenagers during the sexual revolution of the 1960s and were deeply involved in the dramatic changes that characterize family life in the West (DeLamater, 2012; Lin \& Brown, 2012). They now represent what we would describe as the graying of the family revolution. A growing number of people either arrive at old age already divorced or divorce in later life. About a quarter of the divorces in the United States in 2010 were among individuals older than the age of 50, and, among the old, divorcees now outnumber widows and widowers (Brown \& Lin, 2012). Many divorcees wish to have intimate relationships, as do many widows and widowers (Calasanti \& Kiecolt, 2007; Carr, 2004; Moorman, Booth, \& Fingerman, 2006), but few are interested in remarrying. In the United States, only $0.6 \%$ of those aged older than 65 are remarried (Cruz, 2012; see also Mahay \& Lewin, 2007). 
These trends are reflected to some degree in current gerontological and family research; the intimate relationships of older unattached or single persons can no longer be described as a neglected topic of research, as was the case a quarter of a century ago (McElhany, 1992; see also Bulcroft \& Bulcroft, 1991; Cooney \& Dunne, 2001). Although still relatively limited, research on intimacy in later life has expanded to include a broader range of topics, for example, late-life romantic relationships (e.g., Malta \& Farquharson, 2014), including the experiences of older women (e.g., Dickson, Hughes, \& Walker, 2005) and older widows and widowers (e.g., Carr, 2004), the impact of aging on gay and lesbian romantic relationships (e.g., Averett, Yoon, \& Jenkins, 2011), intimacy in long-term care (e.g., Frankowski \& Clark, 2009), later life online dating (e.g., Coupland, 2000), second couplehood (e.g., Koren \& Eisikovits, 2011; Koren \& Simhi, 2016), and living apart together, that is, intimate relationships that do not involve sharing a common home.

Our aim in this critical review is to examine living apart together as an alternative intimate relationship among older persons and to offer a conceptual framework and research agenda that will further comparative research. Central to our discussion is the debate on whether living apart together (LAT) is a new method of intimacy or simply a step on the way to cohabiting or marrying. Addressing this debate requires specification of the life stage under study. We argue that the unique situations of LAT later in life are in keeping with LAT as a new family form. As a relatively new type of intimate partnership, LAT faces unique challenges; couples must negotiate their relationships in social contexts that may question the legitimacy of LAT to the point of viewing it as a deviant arrangement in some countries. We begin by presenting ambivalence and concepts from the life course perspective as a useful framework for studying LAT. We apply this model to a critical assessment of the LAT literature, starting with definitional variations that hinder progress on this topic. We conclude by proposing research questions that we believe will advance the comparative study of living apart together in later life, what we term LLAT.

\section{Conceptual Framework}

As in many new, rapidly expanding areas of social science research, the study of LAT is dominated by smaller exploratory studies and lacks common terminology and elaborated theoretical threads. A central dynamic of all relationships is how they are negotiated. Ambivalence is a particularly useful concept for exploring how the contradictions between expected and new ways of engaging in committed intimate relationships are negotiated. Ambivalence occurs at multiple levels, including the micro level of individuals and relationships, the meso level of social institutions including those concerning intimate relationships, and the macro level of structured social relations, sociolegal, economic, political, and cultural arrangements (Connidis, 2012, 2015; Connidis $\&$ McMullin, 2002b, 2002a). The concept of ambivalence emphasizes "the coexistence of contradictory sentiments, expectations, and forces as characteristic of family and of social life" (Connidis, 2015, p. 77) and explores how these contradictions are and can be negotiated by individuals and through social change. Thus, ambivalence goes beyond mixed feelings about a partner or about LAT to considering how the contradictions of LAT itself are constructed and negotiated in a multilevel context.

Applying ambivalence to LAT relationships helps to bridge various efforts to explore LAT and LAT-like relationships such as dating and to connect LAT to other family relations and to social institutions and arrangements. Cultural variations in the degree to which marriage is entrenched as the acceptable form of intimate relationship make ambivalence a useful concept for comparative research on LAT later in life. Striking a balance between having a committed relationship and maintaining autonomy (Karlsson \& Borell, 2005; Upton-Davis, 2012)—a central contradiction of LAT-is a source of ambivalence negotiated by individuals and couples in the context of social arrangements that promote marriage and, more recently, cohabitation. Contradictions at the level of structured social relations also underscore the differential appeal and accessibility of LAT as an option, for example, based on gender and class. Recent treatments of agency that emphasize its connection to social constraints are central to the concept of ambivalence (Connidis, 2012, 2015) and to the life course perspective (Settersten, 2003).

Placing LAT relationships in a life course perspective helps to clarify the unique features of LLAT. The concepts of life stage and linked lives (Heinz, 2001) are especially relevant to 
studying LAT across the life course. Circumstances and reasons for forming unions at different life stages vary markedly (Upton-Davis, 2012). Among younger adults, many still aim for forging a secure economic future and having children, goals that make cohabitation and marriage more probable objectives. At this life stage, the primary family links of single persons are to parents and siblings, ties that in most cases are either sources of support (parents) or resource neutral (siblings). Consequently, for many at this life stage today, LAT is regarded as a temporary arrangement either because couples are still determining whether they are committed enough to move in together or because they are living with parents while working toward financial independence and being able to live together.

In contrast, among older single persons, most have already had a long-term union, usually marriage, that ended either in the death of a partner or dissolution of the relationship. The majority of these unions resulted in children and grandchildren who remain the primary family links for older parents. Building financial security and having more children are rarely the goals of having an intimate relationship. Indeed, some state-sponsored income programs for seniors penalize recipients who marry. Instead, the desire for companionship and intimacy are primary motivators. Unlike younger adults, the primary family link of single older adults - children-involves ongoing responsibility. Older parents typically continue to offer support and protect their resources for the current and eventual use of their children. Some of the young old also have parents, but by this stage of life, their very old parents are more likely to be receiving than giving support.

In sum, ambivalence and concepts from the life course perspective encourage connections between multiple levels of analysis and attention to the dynamics of relationships beyond individuals and dyads. The concept of ambivalence focuses our attention on the dynamics of LLAT relationships, their impact on extended family dynamics, and their connection to social and cultural arrangements. Life stage and linked lives create quite different circumstances across age cohorts that are pivotal to understanding varying approaches to intimate relationships, including LAT, across the life course. Yet, as we shall see, studies of LAT relationships often fail to differentiate among age cohorts and the degree to which LAT is considered an alternative intimate tie or a temporary situation.

\section{WHAT Is LAT?}

Notable cultural differences in the extent to which LAT is an identified and accepted intimate relationship are reflected in linguistic variations that inhibit a common focus and research agenda. In the United States, expressions used to describe long-term intimate relationships between older singles are often borrowed from teenage culture. When older U.S. respondents in Talbott's (1998) study of romantic relationships used expressions such as "dating" or "going steady," they often qualified them with reservations about their inappropriateness. "It sounds nuts," said one of Talbott's respondents (1998, p. 446) "for an old lady to have a boyfriend" (see also Benson, 2013; Benson \& Coleman, 2016a; Brothers, 2015; Carr, 2004; for Great Britain, see Coulter \& Hu, 2015; Haskey, 2005). Similarly, LAT partners in a qualitative Canadian study (Kobayashi, Funk, \& Khan, 2016) struggled to find a good term for their partner, disliking the terms boyfriend or girlfriend because of their failure to reflect the strength of their relationship.

In contrast, LAT relationships have an ontological status in Sweden, Norway, the Netherlands, and Belgium. In Norway and Sweden, the expression sarbo or särbo, meaning "to live apart" have been in common use for some time and describe long-term intimate relationships that do not include a shared home. The term $L A T$ was first used in the late 1970s by a Dutch journalist referring to a movie in which two people shared a common relationship but not a common home. Besides being an acronym, the word lat in Dutch also means stick (Levin, 2004). In Belgium and the Netherlands, LAT has become generally accepted in everyday use. When the language provides us with a typified meaning of this relationship, LAT becomes part of accepted, commonsense knowledge (see Schutz, 1972) and can be discussed, considered, and assessed as a realistic alternative to other forms of intimate ties (Borell \& Karlsson, 2003).

Against this backdrop, it is not surprising that such a large proportion of the research on older LAT couples is from Belgium (e.g., Lyssens-Danneboom \& Mortelmans, 2015), the Netherlands (e.g., de Jong Gierveld, 2004), Norway (e.g., Levin, 2004), and Sweden (e.g., 
Karlsson \& Borell, 2002). Only recently have researchers in Australia (Upton-Davis, 2012, 2015), Canada (Funk \& Kobayashi, 2016; Kobayashi et al., 2016; Turcotte, 2013), and the United States (Benson, 2013; Benson \& Coleman, 2016a, 2016b; Brothers, 2015) considered LAT a category of intimate relationship in later life worthy of study.

Differences in defining LAT reflect diverse cultural, period, and age-based assumptions about what constitutes both intimacy and commitment. An important challenge to researchers is to develop a definition of LAT that facilitates the study of such relationships regardless of differences in everyday understanding. We favor a definition of LAT that separates LAT as a unique intimate tie considered an end in itself from LAT as a temporary arrangement, ideally on the way to marriage or cohabitation. This follows earlier calls for distinguishing between LAT as a substitute partnership rather than a stepping stone to an established form of partnership (Ermisch \& Siedler, 2008; Upton-Davis, 2012). We define LAT as a chosen, intimate relationship between partners who are committed to LAT and to each other for the long term and who live in separate homes (see Benson \& Coleman, 2016b; de Jong Gierveld, 2002; de Jong Gierveld \& Peeters, 2003; Levin, 2004; Upton-Davis, 2012). Some include the additional provisos that such LAT relationships are sexually active and publicly known (Levin, 2004; Stevens, 2004) and monogamous (de Jong Gierveld, 2002). In our view, the realities versus ideals of sexual activity and monogamy in intimate relationships are subjects to be studied rather than assumed as defining features of them. For example, marriages that are not sexually active or in which partners are sexually active with others are still considered marriages, even if they violate assumptions about ideal marriages.

\section{LAT AND Life Stage \\ Incidence of LAT}

Variations in which criteria are deemed necessary to qualify as LAT result in different sample populations (Duncan \& Phillips, 2011). Statistics about families and intimate relationships are often based on households, so the distribution of LAT relationships has not generally been included in national population surveys (Borell \& Karlsson, 2003; Strohm, Seltzer, Cochran,
\& Mays, 2009). Even in the few cases in which LAT relationships have been included in such surveys or have been studied in other statistically representative samples, different definitions and measures hinder international comparisons.

Estimates of the incidence of LAT relationships in Australia, North America, and West European countries lie in the range of $7 \%$ to $10 \%$ of the population (e.g., Reimondos, Evans, \& Gray, 2011 [Australia]; Duncan \& Phillips, 2011 [Britain]; Milan \& Peters, 2003 [Canada]; Levin, 2004 [Norway]; Strohm et al., 2009 [United States]). Young adults, typically defined as between 20 and 24 years of age, often constitute the largest group categorized as LAT partners in these surveys. In Australia (Reimondos et al., 2011), France (Régnier-Loilier, 2015; Régnier-Loilier, Beaujouan, \& Villeneuve-Gohalp, 2009), and Southern Europe (Billari, Rosina, Ranaldi \& Romano, 2008), half or more of the LAT population is estimated to be younger adults.

Although more common now (see Asendorpf, 2008), LAT relationships among older persons still involve relatively few individuals in midand later life. In Canada, 2.3\% of those older than 60 years of age were LAT partners (Turcotte, 2013), and $4.3 \%$ of those aged 50 to 64 years in the Netherlands (de Jong Gierveld, 2015 ) and $5 \%$ of those older than 60 years of age in Sweden were LAT partners (Bildtgård \& Öberg, 2015). In a statistically representative sample of unmarried, noncohabiting U.S. adults aged 57 to $85,18 \%$ of those aged 57 to $64,14 \%$ of those aged 57 to 85 , and $11 \%$ of those aged 75 to 85 years agreed that they "currently have a romantic, intimate, or sexual partner" (Brown \& Shinohara, 2013, p. 4). Similar to most surveys, this study does not determine how many of those who have an intimate relationship see it as a long-term arrangement or their subjective definition and view of the relationship.

LAT relationships among older people are far more significant than nominal data may imply. Studies from Germany (Asendorpf, 2008), the Netherlands (de Jong Gierveld, 2015), and Sweden (Bildtgård \& Öberg, 2015) indicated that LAT was especially relevant to those who started a new relationship in their old age. In Sweden (Bildtgård \& Öberg, 2015), of those who had started a new intimate relationship after their 60th birthday, 7 of 10 were LAT partners and fewer than 3 of 10 were cohabitants, leaving a 
very small number who had chosen marriage (for similar results in the Netherlands, see de Jong Gierveld, 2004).

\section{LAT: New Family Form or Stepping Stone?}

In some of the literature, LAT relationships are seen as one of the defining aspects of contemporary differentiation of intimacy and family life. This is particularly evident in the work of the pioneer researchers of LAT. As a research concept, LAT was originally launched with a claim to describe "a historically new family form" (Levin, 2004, p. 223; see also Levin \& Trost, 1999). Does a critical review of subsequent empirical research support such a universal claim? Following a life course perspective, we expect LAT relationships to be characterized by a high degree of heterogeneity in terms of subjective meaning, function, and durability that relate in part to life stage (see Benson \& Coleman, 2016b; Coulter \& Hu, 2015).

Qualitative and quantitative studies combine various versions of LAT and multiple age cohorts, making it difficult to focus on LAT as a committed alternative relationship related to life stage. Studies that are ostensibly about LAT are often about LAT as a stepping stone to marriage or cohabiting. For example, in a British study of LAT relationships, defined as "currently in a relationship with someone you are not living with here" (Carter, Duncan, Stoilova, \& Phillips, 2015, p. 579), only 6 of the 50 respondents would fit our definition of LAT because they were the only ones who considered LAT a preferred and committed relationship.

Young adults who LAT usually intend to establish a common home, but cannot do so at present because of practical barriers such as a housing shortage, unemployment, or different locations for work or school (Reimondos et al., 2011 [Australia]; Liefbroer, Poortman, \& Seltzer, 2015 [France and Germany]; Dommermuth, Noack, \& Wiik, 2009 [Norway]). Recurring recessions have meant that young adults who cannot establish themselves in the labor or housing markets are often obliged to return to their parents' home instead of setting up a household with their partner (Connidis, 2014). Those who intend to live with their partner once current impediments are resolved or because they are uncertain about their relationship are more accurately viewed as being in a testing period or passing phase than in a long-term committed relationship. As Duncan and Phillips (2011) concluded, steady girlfriend and boyfriend relationships among younger adults who did not live together and commuter relationships when jobs in different locations forced couples apart, are not new.

Many LAT relationships among those with coresident, dependent children are also temporary and involuntary. In this case, consideration of a third party is the impetus for LAT. Single parents, in practice often mothers, choose not to share their home with their partner to preserve the boundary of the family home and to provide continuity for and avoid conflict with their coresident children (de Jong Gierveld \& Merz, 2013). Single parents may also be concerned about the reaction of others such as parents or former partners who may consider it inappropriate to have a live-in partner or view it as grounds to withdraw financial support. Another third party-a parent who requires care-leads some adult children, in practice often adult daughters, to delay living with a new partner while looking after their elderly parent (see Régnier-Loilier et al., 2009; Reimondos, 2011). With longer lives, these children may be old themselves.

Waiting to cohabit while in a LAT relationship creates its own contradictions, and couples must negotiate the ambivalence of their goal to live together with their current realities. Older persons too may be reluctant to engage openly in nonnormative romantic relationships such as LAT, but they are more likely to keep them secret or provide justifications for them (Koren \& Eisikovits, 2011; Kobayashi et al., 2016) than to be deterred from LAT altogether. Here, the ambivalence created by engaging in a relationship that is not socially accepted is managed through accounts and secrecy.

Regarding durability, although LAT relationships between young to middle-aged partners are often transitional, the LAT relationships of older couples are typically long term. In Canada (Turcotte, 2013), young adults (20-29 years) averaged 2.3 years together, whereas older adults (older than 60 years) averaged 7.5 years. In a Swedish study, all 116 LAT partners aged 60 to 90 years described their relationship as long term, with a median length of 7 years and a range from 1 to 28 years (Karlsson \& Borell, 2002). Differences in relationship duration are even more marked in longitudinal studies. In a study in France (Régnier-Loilier, 2015), only one in 10 of the young couples was still 
LAT 3 years after the first interview, and virtually none 3 years later. The majority had either moved to a common household (36\% with the same person) or separated. In contrast, only $7 \%$ of seniors had moved in with their partner, more than half of them were still in their original LAT relationship after 3 years, and about a third after 6 years; the balance experienced the death of or separation from their LAT partner.

\section{Choosing to LAT: Later Life LAT Relationships as a New Family Form}

The greater durability of older couples' LAT relationships reflects their preference for this type of intimate tie. At this life stage, LAT is neither primarily a practical necessity nor a step toward establishing a common home. A British study of LAT that identified one category of participants who both preferred and were committed to LAT (Carter et al., 2015) suggests that commitment has two elements: commitment to LAT as a form of intimate relationship and commitment to one's LAT partner. In an Australian study (Reimondos et al., 2011), more than 70\% of older LAT partners had chosen to LAT over any other type of relationship. A British study that distinguished between partner LAT couples and dating LAT couples found that those aged 65 to 97 years fell entirely in the partner LAT category, and those aged 55 to 64 years were twice as likely to be partners rather than daters (Duncan \& Phillips, 2011).

Committed or intrinsic LAT partners in Belgium have features that parallel normative views of marriage as involving a strong sense of being in a couple with a deep emotional investment in commitment, loyalty, being together, and mutual respect (Lyssens-Danneboom \& Mortelmans, 2015). For most of the 116 older LAT partners in a Swedish study, the overwhelming motive for LAT was the intimacy of the relationship; LAT partners regarded their relationships as deeply intimate, marked by mutual trust, understanding, and the sharing of confidences (Borell \& Karlsson, 2003). Almost all of the LAT partners had daily contact with one another via telephone, more than one third (36\%) met almost daily, and another half met a couple of times a week (Karlsson \& Borell, 2002). Most of the older LAT couples in a British study (Coulter \& Hu, 2015) lived within an hour of each other, with two thirds less than 30 minutes apart, and saw each other at least once a week, with two thirds seeing their partner daily or several times a week.

Variations in the terminology that British LAT partners who view themselves as couples use to describe their relationship suggest greater commitment among older couples; they more often used the terms partner or husband or wife, and younger persons more often used girlfriend or boyfriend (Duncan, Carter, Phillips, Roseneil, \& Stoilova, 2014). In Swedish (Karlsson \& Borell, 2002) and Belgian (Lyssens-Danneboom \& Mortelmans, 2015) studies of LAT, fidelity was generally seen as a prerequisite for the relationship, a view also supported by a survey of LAT partners in Britain in which $87 \%$ thought it would be wrong if a LAT partner had sex with someone else (Duncan et al., 2014; see also Carter et al., 2015). In a U.S. study (Brothers, 2015) even sexually active older LAT couples viewed sex as a less significant component of their relationship than they did when in marriages earlier in their lives. The assumption of greater freedom coupled with monogamy between couples who do not live together requires an added degree of trust-another paradoxical element of LAT (Kobayashi et al., 2016).

Cohort differences in LAT echo earlier U.S. research on dating that found almost half of respondents aged 55 to 75 years and older described their dating relationship as "steady" and only a small number considered it a step toward marriage, leading the authors to conclude that "dating is taken seriously by older adults but not as a means to marriage," especially by women (Bulcroft \& Bulcroft, 1991, p. 258; see also Bulcroft \& O'Connor, 1986). Watson and Stelle (2011) found that "young old" women did not see dating as a step toward remarrying, even in cases when dating developed into a steady, long-term relationship; a steady, long-term relationship, not marriage, was their goal. Older adults in the United States seriously pursue romantic partners (Stephure, Boon, MacKinnon, \& Deveau, 2009), and, when compared with the personal ads and dating profiles of younger adults, they are less future oriented and more focused on present concerns (Alterovitz \& Mendelsohn, 2013).

Counter to normative assumptions about marriage, older Belgian LAT couples also valued autonomy, time on their own, economic independence, and maintaining territorial boundaries (Lyssens-Danneboom \& Mortelmans, 2015). 
Older Swedish couples also emphasized autonomy as a prime motivator for LAT (Borell \& Karlsson, 2003). Similar to LAT couples, later life dating women "prided themselves on their independence and did not want to give it up" (Dickson et al., 2005, p. 73). Analyses of personal online ads generally confirm that older women are seldom prepared to compromise their independent lifestyle with a new marriage (e.g., Levesque \& Caron, 2004; McWilliams \& Barrett, 2014).

The low level of organization of LAT relationships and the absence of many of the commitments and ties that characterize marriage (Yodanis \& Lauer, 2014) put the focus on the emotional side of the relationship (Borell \& Karlsson, 2003). In theory at least, LAT simultaneously gives both partners autonomous access to their resources and home along with access to strong mutual commitment and intimacy. Partners defined as being in intrinsic LAT relationships in a Belgian study (Lyssens-Danneboom \& Mortelmans, 2015, p. 19) "operate as two autonomous individuals with their own objectives (maintaining autonomy and freedom) and cooperated ... to achieve a common goal (the mutual provision of intimacy, companionship and support)." LLAT relationships exemplify one of the features of Giddens' (1991) ideal type of "pure" relationship; to a relatively high degree they depend on "satisfactions or rewards generic to that relationship itself" (p. 224).

Among older persons, priorities shift as the responsibilities of raising children and paid work diminish. A limited future increases a preference for affectively rich relationships (Carstensen, 1995). LLAT is well suited to this psychological process. Emotional content is brought to the fore, and, in contrast to marriage, the automatic development of increasing commitments and responsibilities is not assumed (de Jong Gierveld, 2004; Karlsson \& Borell, 2002). At the same time, among Swedish LLAT partners, reciprocal emotional support was accompanied with almost daily practical support (Karlsson \& Borell, 2002), and they received more support from their LLAT partner than from any other person in their network, including children and grandchildren (Karlsson, Johansson, Gerder, \& Borell, 2007).

Most older persons who LAT are previously married parents (Karlsson \& Borell, 2002; Karlsson et al., 2007; see also de Jong Gierveld \& Merz, 2013). Unlike younger adults, LAT is chosen for its good fit with their current life stage and their links to adult children. Participants in a qualitative U.S. study of 59- to 89-yearolds in LLAT relationships (Brothers, 2015) viewed marriage as a relationship associated with the life stage of having children. A 65-year-old widowed mother of two observed the following:

I think that if you are raising children ... it makes good sense to have a committed relationship that works together to raise these kids. But outside of that, I don't really see where marriage has a reason. (Brothers, 2015, p. 64)

Brothers (2015) concluded that older persons in LLAT relationships were engaged in a new family form that contrasted with the focus on gendered family formation and child rearing in their earlier marriages.

A multilevel conception of ambivalence encourages us to link agency to structure and emphasizes variations in opportunities for exercising particular choices. LAT relationships among older couples reflect class-based differences that make the capacity to run two homes more likely among those with more resources. Among younger couples, LAT often occurs because a couple cannot afford their own home and, therefore, lives with others (often parents) until they can (Coulter \& Hu, 2015). In cases where coresidence in old age means forfeiting public funding, then those with fewer resources may be more likely to choose to LLAT.

Gender also shapes the appeal of LAT later in life. The pull of linked lives and responsibilities to others is gendered, with women more likely to experience consequent limits on agency in the types of intimate relationships that are compatible with these commitments (de Jong Gierveld \& Merz, 2013; Upton-Davis, 2015). Women who can afford to maintain a separate home appear to be more motivated than men to be in LLAT relationships as a way of avoiding the gendered arrangements that they experienced in earlier marriages (Brothers, 2015; Upton-Davis, 2012). Swedish research (Karlsson \& Borell, 2002) showed that women were significantly more motivated to choose LAT to secure independence and avoid a traditional gendered division of labor. Whether women regarded their previous marriage as "happy" or "unhappy," they often saw their shared home as representing responsibility rather than freedom and work rather than relaxation. 
Among repartnered adults aged 50 and older in the Netherlands (de Jong Gierveld \& Merz, 2013), women, older participants, and parents were more likely to LAT than to remarry or cohabit. Women were also motivated to LAT as a way of protecting their financial assets (de Jong Gierveld, 2002). A Canadian qualitative study of LAT couples involving mostly divorced partners (Funk \& Kobayahsi, 2016) also found that women saw LAT as a way to avoid gendered household tasks and partner nurturing and to protect autonomous decision making about finances and the home. Men did not make parallel observations. Australian work by Upton-Davis (2015) involving women 45 years of age and older showed the appeal of LAT as a transformative option that allowed for a more egalitarian intimate relationship marked by independence and a positive view of oneself.

The role of women in establishing LAT relationships can be seen as a result of the influence that earlier experiences have on choices made in later life (Elder, 1994). If their previous marital households were a constitutive force in the reproduction of traditional gendered relations, their own household today is a resource base from which they may avoid an asymmetrical distribution of household labor and unequal demands of caring for a partner (Borell \& Karlsson, 2003; Brothers, 2015). The ambivalence of enjoying a committed intimate relationship that threatens egalitarianism in household labor is resolved by LAT. LAT relationships can also be a method of resolving ambivalent views about cohabiting (Roseneil, 2006) and competing desires to both stay in a preferred neighborhood and engage in an intimate relationship (Coulter \& Hu, 2015).

Social policies that rest on the assumption that couples have their own safety net-each other-are motivators to LAT, especially among women. In this case, institutionalized policy tends to reinforce gender and class relations. For example, in Sweden, decreased access to public social services has made it increasingly difficult for couples who live together to get assistance. Accordingly, Swedish women who LAT tend to see a home of their own as a protection against potential societal demands that partners provide the care that would otherwise be the responsibility of local welfare services. For those who cannot afford to forfeit public funding, there is also a push toward LAT.

\section{Proposed Research Agenda}

Our critical review establishes that LAT in older age is characteristically different from LAT at earlier life stages, making LAT more in keeping with a new family form than a transitory coping mechanism in later life. Research on dating in the United States shows parallel life stage differences. Although younger adults generally view and experience LAT as a temporary situation, older ones typically seek it out as an end in itself and aim to negotiate long-term, stable LAT relationships. For this reason, we propose the acronymn LLAT to emphasize the unique features of LAT in later life.

Does the fact that LAT is usually a durable relationship for older couples but a flexible arrangement for younger ones (Coulter \& Hu, 2015) mean that older couples in LLAT relationships never marry? Not necessarily, but just as marriage is considered marriage even though it might end in divorce or widowhood later on, so a committed LLAT relationship is a LLAT relationship even if it might result in marriage later on. In the meantime, for both LLAT and marriage, the accepted definition of the situation at the time has consequences for the partners in the relationship and for those in their social networks. The possibility of change does not deny the power of currently living apart together or being married if the couples involved consider their relationship a long-term arrangement.

Our focus has been on LLAT relationships in which both partners have chosen to be in a committed relationship that protects autonomy and limits obligations. Choice or agency refers to acting on one's own behalf in the context of available alternatives, that is, agency-within-structure (Connidis, 2012, 2015; Settersten, 2003). LAT partners who defend their choice to LAT rather than marry because of their emotional commitment or financial, parental, or legal situations were described in a Canadian study as displaying interpretive agency (Kobayashi et al., 2016). Unveiling the fact that some women enter into LAT relationships because they feel constrained or vulnerable rather than doing so as a consequence of reflexive and strategic choices (Duncan, 2015) does not negate the fact that they have chosen to LAT as their best available alternative. Seeing such vulnerability or constraint as motivators unique to LAT also ignores the reality that many women (and men) enter marriage for similar reasons. The unique contradictions of choosing 
to LAT when another form of relationship is preferred and their negotiation are topics for further research.

LLAT can be viewed as a way of resolving the ambivalence that older persons may have about both cohabiting and marrying, but LLAT has its own contradictions that require negotiation. The term itself suggests the contradiction inherent in negotiating a committed, intimate relationship (togetherness) without coresiding (apartness) in cultures where coresidence has been a defining feature of intimate ties (Stoilova, Roseneil, Crowhurst, \& Santos, 2014). As is true of all families of choice, LAT relationships involve ambivalence in the tensions between critique and transformation and between belonging and exclusion (Pidduck, 2009).

Among couples that include one partner who prefers to LAT and another who would rather live together (see, e.g., Duncan et al., 2014), the ambivalence of negotiating a committed relationship in separate households is compounded by contradictory goals between partners. For LAT couples in which both partners want to LAT because they value a committed intimate relationship combined with autonomy and limited obligation, the ongoing challenge is to negotiate this paradox.

As is often true of applications of ambivalence to family ties, reference to ambivalence in LLAT relationships is usually at the micro level of mixed feelings. Some LLAT partners and couples experience ambivalence about the appropriateness of LAT (Benson \& Coleman, 2016b) and about care exchanges (de Jong Gierveld, 2015). Such ambivalence is focused on the micro level of psychological feelings but can be related to institutionalized expectations regarding what constitutes a committed relationship and to broader structural issues such as gender and class.

Ambivalence about LLAT is likely to vary based on the degree to which a culture and society view marriage as the proper or ideal intimate relationship. In Great Britain, marriage remains the overwhelming favorite (Duncan et al., 2014). Negotiating LLAT in the context of established understandings of what comprises a real and socially accepted committed relationship creates ambivalence for some individuals who LAT, particularly in countries where LAT is a relatively new alternative. In a U.S. qualitative study of 25 LAT partners (Benson \& Coleman, 2016b), those who are still coming to terms with merging LAT with normative views of what constitutes a romantic relationship are characterized as ambivalent. The absence of an accepted term for LAT in the United States noted by partners trying to find appropriate titles for one another (Benson \& Coleman, 2016a; Brothers, 2015) reflects cultural variations in the extent to which LAT is a recognized and accepted intimate tie and in the likelihood of institutionalizing LAT, comparative topics that warrant further study. These variations in turn help to account for different levels of ambivalence associated with LAT.

Explorations of alternative intimate relationships that lapse into traditional ideas of "good partnerships" as those in which partners feel obliged to care for one another (see, e.g., de Jong Gierveld, 2015) highlight the socially constructed ambivalence that couples who LLAT must negotiate. The assumption that being a good partner includes the obligation to provide extensive care challenges the legitimacy of intimate ties where this is not a premise. Yet if partners choose LAT in part because they prefer not to assume care obligations, then they are being the kind of good partners they had agreed to become by not expecting to either give or accept care. What is the experience of LLAT partners when the need for care arises?

At the heart of LAT is the contradictory aim of having a long-term, committed, intimate relationship while preserving autonomy and minimizing obligations to give and receive care. Circumstances that threaten the balance of intimacy and independence, such as the declining health of a partner, are likely to heighten ambivalence in LLAT relationships (see Connidis, 2015). Indeed, LAT partners themselves express ambivalence about the impact that future care needs may have on their relationship (Kobayashi et al., 2016). What happens if a partner's situation changes and more extensive support is needed? How do couples negotiate this contradiction and how are other family members implicated in this negotiation?

There are no longitudinal studies that can show the actual extent of care commitments between LLAT partners over time. Studies in Sweden (Karlsson et al., 2007) and the Netherlands (de Jong Gierveld, 2015) were more or less hypothetical, as the respondents had generally not been faced with the challenge of a seriously ill partner. When asked to envisage a future scenario in which their partner is seriously ill, 
respondents had higher expectations of receiving care from their LLAT partner than from their relatives, and none of them would consider ending their LLAT relationship because their partner became ill (Karlsson \& Borell, 2002; Karlsson et al., 2007). Most, however, envisaged caring for an ill LAT partner a few days a week or a few hours a day, not full-time.

Belgian data (Lyssens-Danneboom \& Mortelmans, 2015) showed that LAT partners considered their partners as providers of emotional support and care, but there were signs of ambivalence about the ability to meet future care needs. A British study (Duncan et al., 2014) that relied on hypothetical views of future care provision found that slightly more than one quarter of those in chosen LAT relationships believed that their partner would care for them were they "ill in bed." Men were more likely than women to believe this and, unlike the Swedish study, both men and women were more likely to say that a family member would provide such care. In practice, some LLAT partners had received extensive support when ill.

Research in the Netherlands suggests that the attitudes held by LLAT couples about care exchanges are not matched by their behavior in the face of actual illness (de Jong Gierveld, 2015). LAT partners who had not yet faced the situation of a seriously ill partner often expressed reservations about providing unlimited care, but those who actually had a very ill partner usually provided the same degree of care as would married spouses. This suggests that for some LLAT couples, the resolution of ambivalence is found in favoring the commitment of the relationship over the autonomy of not providing care.

Comparative research should explore variations in how the ambivalence of autonomy and intimacy are resolved when the need for care arises, a transition that is a revealing site for studying ambivalence (Connidis, 2015). The link between policy and LLAT and its impact on negotiating caregiving is an important component of this topic. As Upton-Davis (2012) observed, LLAT also has policy implications for housing if more old people continue to live alone even when in an intimate relationship and for health care arrangements given that one cannot assume that having a partner means receiving care. To date, LLAT among heterosexuals tends to be more common among those with more resources (Upton-Davis, 2015). Given that LLAT appears to be a positive experience for substantial numbers of older persons, particularly women, structural barriers to this option must be explored.

There is a great need for a broader network perspective on the implications of LLAT relationships for the larger constellation of family ties - the issue of linked lives. The desire to protect the inheritance of one's children by not living with an intimate partner often motivates LLAT. Adult children can be influential in decisions to LAT rather than live with a partner (de Jong Gierveld \& Merz, 2013). One's own or a partner's children can sabotage plans to live together and may decrease contact with parents when children hold negative views of their parents engaging in LLAT relationships. Comparisons with continuously married partners found that repartnered couples, especially those who cohabit or LLAT have weaker ties with their children (de Jong Gierveld \& Peeters, 2003). The risk of greater conflict that repartnering in a cohabiting relationship poses (Schenk \& Dykstra, 2012) leads some parents to LAT as a way to resolve the ambivalent goals of engaging in an intimate tie and maintaining closeness with children.

The ambivalence of LLAT relationships reverberates across family ties, raising questions about the boundaries and expectations of others regarding the LLAT partner of a family member. Key assumptions made by LLAT partners in qualitative studies (e.g., Brothers, 2015; de Jong Gierveld, 2015) are that they have made the necessary arrangements for health care, that their children will take care of them if needed, and that their partner's children will care for their partner. From the standpoint of adult children, the fact that a parent is LLAT cannot be assumed to mean future care for their parent if needed. What are the implications of this assumption for negotiating a relationship with a parent's LLAT partner? Is there an effort to develop an emotional bond in the absence of assuming an instrumental one? Does the expansion of networks that LAT potentially allows increase the number of potential care providers (Cherlin, 2010), or is there ambivalence among adult children about offering care to their parent's LLAT partner?

Is a LLAT partner "part of the family" or "my parent's partner"? Variations in the response are likely to parallel those among step ties-much will depend on the duration of the relationship, the extent of shared activity, and the degree of 
emotional attachment that develops over time (Connidis, 2010). A qualitative British study (Stoilova, Roseneil, Carter, Duncan, \& Phillips, 2017) suggested that strong emotional attachment and the view of a LLAT relationship as ongoing enhanced viewing a LLAT partner as part of the family, which often extended to the LLAT partner's family members. In cases where LLAT partners do eventually provide care despite a starting assumption that this would not occur, are the family members, especially children, expected or likely to support their parents' caregiving efforts? Given that some ex-wives care for their ex-husbands, primarily as an expression of their commitment to helping their children (Cooney, Proulx, Snyder-Rivas, \& Benson, 2014), perhaps children of parents who LLAT become implicated in caregiving chains that contradict expectations of filial obligation. How is such ambivalence resolved?

The paradoxical concern about public and legal status in relationships that are sought after for their autonomy and limited obligation is a source of structured ambivalence as LAT couples negotiate committed relationships that lack legal standing (Duncan, Carter, Phillips, Roseneil, \& Stoilova, 2012; LyssensDanneboom, Eggermont, \& Mortelmans, 2013; Lyssens-Danneboom \& Mortelmans, 2015). Lyssens-Danneboom and Mortelmans (2015) found legal insecurity among LLAT partners who were concerned about not having a public identity as a couple and about whether they would have access to their partner should there be a medical problem or accident. At the same time, LLAT partners generally accepted that, upon their partner's death, it would be their partner's family members and not themselves who would be responsible for making subsequent arrangements. The potential cost of legal exclusion is exemplified by a man who was sole care provider to his LLAT partner up to her death, but was then denied partner status by her children (de Jong Gierveld \& Merz, 2013).

Legal status issues parallel long-held paradoxes in committed same-sex relationships in past and present jurisdictions where marriage is not a legal option for sanctioning the relationship. The ambivalence of their social standing as couples may reverberate across the family network when other family members make efforts to claim the legitimacy of a family member's gay or lesbian relationship (Connidis, 2003). Recent research identified mid-life gay and lesbian couples' perceptions of the ambivalent views and actions of other family members regarding their sexual identity and same-sex relationship (Reczek, 2016). Exploring both the actual ambivalence experienced by family members of LLAT partners and LLAT partners' perceptions of ambivalence on behalf of family members would help us to better understand the relational character of ambivalence. As well, ambivalence would be situated in family networks and broader social arrangements rather than in the feeling states of individuals.

As is true of today's LLAT relationships, significant numbers of cohabiting same- and opposite-sex couples once preferred their unofficial relationships precisely because they wanted to avoid both the ideological and practical trappings of marriage. The institutionalization of cohabitating and same-sex relationships in many countries may foreshadow similar changes regarding the legal status of LAT, another potential source of ambivalence. An asset of applying ambivalence to LLAT relationships is to highlight the complexity of choices to LAT and to link the choices that individuals make to the larger social and cultural structures that influence, constrain, or facilitate their choices (Connidis, 2015). If living with a partner did not have legal implications for the subsequent property and resource rights of that partner, a couple might choose to cohabit. Alternatively, if LLAT were more socially accepted, more individuals might choose this option. Ideally, if LLAT becomes more institutionalized, it will not lose its potential as a force for social change, including more egalitarian gender relations (Upton-Davis, 2015).

We are not arguing that ambivalence applies only to LLAT but, rather, that LLAT has some unique ambivalent features. Comparing LAT with marriage, Lyssens-Danneboom and Mortelmans (2015, pp. 19-20) concluded that, unlike marital spouses who are bound to behave "as expected" because they have agreed on "a set of cultural and behavioural guidelines," LAT partners are at risk that they "will enter the relationship with different intentions and expectations." Current divorce rates seem evidence enough that many individuals also begin marriage with intentions and expectations that are a poor fit with those of their spouse. Clearly, LLAT partners have a greater burden of proof to be recognized as a couple based on the content of their relationship, but marital partners 
too must negotiate contradictory expectations of their relationship.

Regarding methods, future explorations of gender and LLAT will benefit from studies that include men and women. Dyadic studies (see Benson \& Coleman, 2016b) that focus on the interaction between LLAT partners would help to address how gender plays out in LAT relationships and whether differing perspectives on LAT are a unique source of ambivalence or a challenge to resolving it. Family constellation studies that include a LLAT couple's extended family, particularly children, would broaden our understanding of family relationship dynamics and the implications of LLAT beyond the couple. To truly explore a life course perspective and the negotiation of ambivalence in LAT relationships over time and in response to life transitions, longitudinal studies are needed. Studies on LLAT should relate the experience of partners, couples, and families to larger social and cultural contexts that enhance a comparative understanding of this intimate tie. Both qualitative and quantitative research shed valuable light on this topic.

\section{CONCLUSION}

Isolating LAT relationships in later life for focused study will enhance our understanding of this intimate tie as a new family form, its challenges, and its implications for family ties, communities, and social change. Living in LAT relationships means different things at different stages of the life course. We conclude that among older but not younger adults, LAT is generally a stable alternative to living with a partner, not a stepping stone to establishing a common home.

Applying ambivalence and life course concepts encourages a multilevel approach to research that links the negotiation of LLAT relationships to the family networks, social institutions, structured social relations, and cultural environments in which they are chosen and worked out. As a new form of intimate tie, LLAT challenges institutionalized intimate relationships and is more open to an uncluttered exploration of how intimate relationships are negotiated. We believe that pursuing our proposed research agenda will extend our understanding of all intimate ties, including marriage, as we study the realities of relationships rather than assumptions made about them as ideal types.

\section{REFERENCES}

Alterovitz, S-R., \& Mendelsohn, G. A. (2013). Relationship goals of middle-aged, young-old, and old-old internet daters: An analysis of online personal ads. Journal of Aging Studies, 27, 159-165. https://doi.org/10.1016/j.jaging2012.12.006

Asendorpf, J. B. (2008). Living Apart Together: Ageand cohort-dependence of a heterogeneous life style (Living Apart Together: Alters-und Kohor tenabhängigkeit einer heterogenen Lebensform). Kölner Zeitschrift fur Soziologie and Sozialpsychologie, 60, 749-764. https://doi.org/10.007/s11 577-008-0035-4

Averett, P., Yoon, I., \& Jenkins, C. L. (2011). Older lesbians: Experiences of aging, discrimination and resilience. Journal of Women and Aging, 23, 16-32. https://doi.org/10.1080/08952841.2011 .587742

Benson, J. J. (2013). From living apart, to living-apart-together: Older adults developing a preference for LAT (Doctoral dissertation). Retrieved from https://mospace.umsystem.edu/ xmlui/bitstream/handle/10355/44653/research .pdf? sequence $=1$

Benson, J. J., \& Coleman, M. (2016a). Older adult descriptions of living apart together. Family Relations, 65, 439-449. https://doi.org/10.1111/fare .12203

Benson, J. J., \& Coleman, M. (2016b). Older adults developing a preference for living apart together. Journal of Marriage and Family, 78, 797-812. https://doi.org/10.1111/jomf.12292

Bildtgård, T., \& Öberg, P. (2015). Changing forms of intimacy among older people in late modern society ( Förändrade imtimitetsformer bland äldre i det senmoderna samhället). Sociologisk Forskning, 51, 5-32.

Billari, F. C., Rosina, A., Ranaldi, R., \& Romano, C. (2008). Young adults living apart and together (LAT) with parents: A three-level analysis of the Italian case. Regional Studies, 42, 625-639. https:// doi.org/10.1080/00343400701543173

Borell, K., \& Karlsson, S. G. (2003). Reconceptualising intimacy and ageing. Living apart together. In: S. Arber, K. Davidson, \& J. Ginns (Eds.), Gender and ageing: Changing roles and relationships (pp. 47-62). Buckingham: Open University Press.

Brothers, D. (2015). “Doing” LAT: Redoing gender and family in living apart together relationships in later life (Doctoral dissertation). Retrieved from http://rave.ohiolink.edu/etdc/view?acc_ num $=$ miami 1429881367

Brown, S. L., \& Lin, I. F. (2012). The gray divorce revolution: Rising divorce among middle-aged 
and older-adults, 1990-2010. Journals of Gerontology, Psychological Sciences and Social Sciences, 67, 731-741. https://doi.org/10.101093/ geronb/gbs089

Brown, S. L., \& Shinohara, S. K. (2013). Dating relationships in older adulthood: A national portrait. Journal of Marriage and Family, 75, 1194-1202. https://doi.org/10.1111/jomf.12065

Bulcroft, K., \& O'Connor, M. (1986). The importance of dating relationships on quality of life for older persons. Family Relations, 35, 397-401. https://doi.org/10.2307/584367

Bulcroft, R. A., \& Bulcroft, K. A. (1991). The nature and functions of dating in later life. Research on Aging, 13, 244-260. https://doi.org/10.1177/ 0164027591132007

Calasanti, T., \& Kiecolt, K. J. (2007). Diversity among late-life couples. Generations, 3, 10-17.

Carr, D. (2004). The desire to date and remarry among older widows and widowers. Journal of Marriage and Family, 66, 1051-1068. https://doi .org/10.1111/J.0022-2445.2004.000.78.x

Carstensen, L. L. (1995). Evidence from a life-span theory of socioemotional selectivity. Current Directions in Psychological Science, 4, 151-156. https://doi.org/10.1111/1467-8721.ep11512261

Carter, J., Duncan, S., Stoilova, M., \& Phillips, M. (2015). Sex, love and security: Accounts of distance and commitment in living apart together relationships. Sociology, 50, 576-593. https://doi.org/ $10.1177 / 0038038515573689$

Cherlin, A. (2010). Demographic trends in the United States: A review of research in the 2000s. Journal of Marriage and Family, 72, 403-419. https://doi .org/10.1111/j.1741-3737.2010.00710.x

Cherlin, A. J., \& Furstenberg, F. (1986). The new American grandparent. New York: Basic Books.

Connidis, I. A. (2010). Family ties \& aging. 2nd ed. Los Angeles: Pine Forge.

Connidis, I. A. (2012). Theoretical directions for studying family ties and aging. In R. Blieszner \& V. H. Bedford (Eds.), Handbook of families and aging (2nd ed.; pp. 35-60). Denver, CO: Praeger.

Connidis, I. A. (2014). Age relations and family ties over the life course: Spanning the macro-micro divide. Research in Human Development, 11, 291-308. https://doi.org/10.1080/15427609.2014 .967050

Connidis, I. A. (2015). Exploring ambivalence in family ties: Progress and prospects. Journal of Marriage and Family, 77, 77-95. https://doi.org/10 .1111 jomf. 12150

Connidis, I. A., \& McMullin, J. A. (2002a). Ambivalence, family ties, and doing sociology. Journal of Marriage and Family, 64, 594-601. https://doi.org/10.1111/j.1741-3737.2002.00594.x

Connidis, I. A., \& McMullin, J. A. (2002b). Sociological ambivalence and family ties: A critical perspective. Journal of Marriage and Family, 64,
558-567. https://doi.org/10.1111/j.1741-3737. 2002.00558.x

Cooney, T. M., \& Dunne, K. (2001). Intimate relationships in later life. Current realities, future prospects. Journal of Family Issues, 22, 838-858. https://doi.org/10.1177/019251301022007003

Cooney, T. M., Proulx, C. M., Snyder-Rivas, L. A., \& Benson, J. J. (2014). Role ambiguity among women providing care for ex-husbands. Journal of Women and Aging, 26, 84-104. https://doi.org/10 $.1080 / 08952841.2014 .859502$

Coulter, R., \& Hu, Y. (2015). Living apart together and cohabitation intentions in Great Britain. Journal of Family Issues. Advance online publication. https://doi.org/10.1177/0192513X15619461

Coupland, J. (2000). Past the "perfect kind of age"? Styling selves and relationships in over-50s dating advertisements. Journal of Communication, 50, 9-30. https://doi.org/10.1111/J.1460-2466.2000 .tb02850.x

Creasey, G. L. (1993). The association between divorce and late adolescent grandchildren's relations with grandparents. Journal of Youth and Adolescence, 22, 513-529. https://doi.org/10. 1007/BF01537713

Cruz, J. (2012). Remarriage rate in the U.S., 2010 (Family Profile no. FP-12-14). Bowling Green, OH: National Center for Family \& Marriage Research.

de Jong Gierveld, J. (2002). The dilemma of repartnering: Considerations of older men and women entering new intimate relationships in later life. Ageing International, 27, 61-78. https://doi.org/10. 1007/s12126-002-1015-z

de Jong Gierveld, J. (2004). Remarriage, unmarried cohabitation, living apart together: Partner relationship following bereavement or divorce. Journal of Marriage and Family, 66, 236-243. https:// doi.org/10.1111/j.0022-2445.200400015.x

de Jong Gierveld, J. (2015). Intra-couple caregiving of older adults living apart together: Commitment and independence. Canadian Journal on Aging, 347, 356-365. https://doi.org/10.1017/ S0714980815000264

de Jong Gierveld, J., \& Merz, E. (2013). Parents' partnership decision making after divorce or widowhood: The role of stepchildren. Journal of Marriage and Family, 75, 1098-1113. https://doi .org/10.1111/jomf.12061

de Jong Gierveld, J., \& Peeters, A. (2003). The interweaving of repartnered older adults' lives with their children and siblings. Ageing \& Society, 23, 187-205. https://doi.org/10.1017/ S0144686X02001095

DeLamater, J. (2012). Sexual expression in later life: A review and synthesis. Journal of Sex Research, 49, 125-141. https://doi.org/10.1080/00224499 .2011 .603168 
Dickson, F. C., Hughes, P. C., \& Walker, K. L. (2005). An exploratory investigation into dating among later-life women. Western Journal of Communication, 69, 67-82. https://doi.org/10.1080/ 10570310500034196

Dommermuth, L., Noack, T., \& Wiik, K. A. (2009). Samlivsetablering-nye og vedvarende mønstre: Gift, samboer eller bare kjærester?" [Union formation-new and constants pattern: married, cohabiting or just boyfriend/girlfriend?]. Samfunnsspeilet, 23, 13-19, Retrieved from http:// www.ssb.no/ssp/utg/200901/ssp.pdf

Duncan, S. (2015). Women's agency in living apart together: Constraint, strategy and vulnerability. The Sociological Review, 63, 589-607. https://doi .org/10.1111/1467-954X.12184

Duncan, S., Carter, J., Phillips, M., Roseneil, S., \& Stoilova, M. (2012). Legal rights for people who "live apart together"? Journal of Social Welfare and Family Law, 34, 443-458. https://doi.org/10 $.1080 / 09649069.2012 .753731$

Duncan, S., Carter, J., Phillips, M., Roseneil, S., \& Stoilova, M. (2014). Practices and perceptions of living apart together. Family Science, 5, 1-10. https://doi.org/10.1080/19424620.2014.927382

Duncan, S., \& Phillips, M. (2011). People who live apart together (LATs): New family form or just a stage? International Review of Sociology, 21, 513-532. https://doi.org/10.1080/03906701.2011 .625660

Elder, G. H. (1994). Time, human agency, and social change: Perspectives on the life course. Social Psychology Quarterly, 57, 4-15.

Ermisch, J., \& Siedler, T. (2008). Living apart together. In M. Brynin \& J. Ermisch (Eds.), Changing relationships (pp. 29-43). Hoboken, NJ: Routledge.

Frankowski, A. C., \& Clark, L. J. (2009). Sexuality and intimacy in assisted living: Residents' perspectives and experiences. Sexuality Research and Social Policy, 6, 25-37. https://doi.org/10.1525/ srsp.2009.6.4.25

Funk, L. M., \& Kobayashi, K. M. (2016). From motivations to accounts: An interpretive analysis of "living apart together" relationships in mid- to later-life couples. Journal of Family Issues, 37, 1101-1122. https://doi.org/10.1177/ $0192513 X 14529432$

Giddens, A. (1991). Modernity and self-identity: Self and identity in late modern age. Cambridge, UK: Polity Press.

Haskey, J. (2005). Living arrangements in contemporary Britain: Having a partner who usually lives elsewhere and living apart together (LAT). Рориlation Trends, 122, 35-45.

Heinz, W. (2001). Work and the life course: A cosmopolitan-local perspective. In V. W. Marshall, W. R. Heinz, H. Kruger, \& A. Verma (Eds.),
Restructuring work and the life course (pp. 3-22). Toronto: University of Toronto Press.

Karlsson, S. G., \& Borell, K. (2002). Intimacy and autonomy, gender and ageing. Ageing International, 27, 11-26. https://doi.org/10.1007/s12126002-1012-2

Karlsson, S. G., \& Borell, K. (2005). A home of their own: Women's boundary work in LAT-relationships. Journal of Aging Studies, 19, 73-84. https://doi.org/10.1016/j.jaging.2004 .03 .008

Karlsson, S. G., Johansson, S., Gerdner, A., \& Borell, K. (2007). Caring while living part. Journal of Gerontological Social Work, 49, 3-27. https://doi .org/10.1300/J083v49n04_02

Kobayashi, K. M., Funk, L., \& Khan, M. M. (2016). Constructing a sense of commitment in "living apart together" (LAT) relationships: Interpretive agency and individualization. Current Sociology. Advance online publication. https://doi.org/10 $.1177 / 0011392116653237$

Koren, C., \& Eisikovits, Z. (2011). Life beyond the planned script: Accounts and secrecy of older persons in second couplehood in old age in a society in transition. Journal of Social and Personal Relationships, 28, 44-63. https://doi.org/10.1177/ 0265407510385430

Koren, C., \& Simhi, S. (2016). "As long as it's good": An intergenerational family perspective of bridging gaps between reality and ideality of second couplehood as a problem and as a solution. Ageing \& Society, 36, 716-740. https://doi.org/10.1017/ So144686X4001482

Levesque, L. M., \& Caron, S. L. (2004). Dating preferences of women born between 1945 and 1960. Journal of Family Issues, 25, 833-846. https://doi .org/10.1177/0192513X03258300

Levin, I. (2004). Living Apart Together: A new family form. Current Sociology, 52, 223-240. https://doi .org/10.1177/0011392104041809

Levin, I., \& Trost, J. (1999). Living Apart Together. Community, Work and Family, 2, 279-293. https:// doi.org/10.1080/13668809908412186

Liefbroer, A. C., Poortman, A., \& Seltzer, J. A. (2015). Why do intimate partners live apart? Evidence on LAT relationships across Europe. Demographic Research, 32, 251-286. https://doi.org/10 .4054/DemRes.2015.32.8

Lin, I-F. \& Brown, S. L. (2012). Unmarried Boomers confront old age: A national portrait. The Gerontologist, 52, 153-165. https://doi.org/10.1093/ geront/gnr141

Lyssens-Danneboom, V., Eggermont, S., \& Mortelmans, D. (2013). Living apart together (LAT) and law: Exploring legal expectations among LAT individuals in Belgium. Social \& Legal Studies, 22, 357-376. https://doi.org/10.1177/ 0964663913478960 
Lyssens-Danneboom, V., \& Mortelmans, D. (2015). Living apart together: Longing for the couple, enjoying being single. Family Science, 6, 11-22. https://doi.org/10.1080/19424620.2015.1009932

Mahay, J., \& Lewin, A. C. (2007). Age and desire to marry. Journal of Family Issues, 28, 706-723. https://doi.org/10.1177/0192513X06297272

Malta, S., \& Farquharson, K. (2014). The initiation and progression of late-lite romantic relationships. Journal of Sociology, 50, 237-251. https://doi.org/ $10.1177 / 144078331242254$

McElhany, L. J. (1992). Dating and courtship in later years: A neglected topic of research. Generations, 16, 21-23.

McWilliams, S., \& Barrett, A. E. (2014). Online dating in middle and later life: Gendered expectations and experiences. Journal of Family Issues, 35, 411-436. https://doi.org/10.1177/ $0192513 X 12468437$

Milan, A., \& Peters, A. (2003). Couples living apart. Canadian Social Trends, Summer, 2-6.

Moorman, S. M., Booth, A., \& Fingerman, K. (2006). Women's romantic relationships after widowhood. Journal of Family Studies, 27, 1281-1304. https:// doi.org/10.1177/0192513x06289096

Pidduck, H. (2009). Queer kinship and ambivalence: Video autoethnographies by Jean Carlomusto and Richard Fung. GLQ: A Journal of Lesbian and Gay Studies, 15, 441-468. https://doi.org/10.1215/ 10642684-2008-031

Reczek, C. (2016). Ambivalence in gay and lesbian family relationships. Journal of Marriage and Family, 78, 644-659. https://doi.org/10.1111/jomf .12308

Régnier-Loilier, A. (2015). Neither single nor in a couple in France: What became of them three and six years later? In D. Mortelmans, I. Pasteels, A. Régnier-Loilier, D. Vignoli, \& S. Mazzuco (Eds.), Analysis of determinants and prevalence of LAT (pp. 29-53). Rostock, Germany: Max Planck Institute for Demographic Research.

Régnier-Loilier, A., Beaujouan, É., \& VilleneuveGohalp, C. (2009). Neither single, nor in a couple: A study of living apart together in France. Demographic Research, 21, 75-108. https://doi.org/10 .4054/DemRes.2009.21.4

Reimondos, A., Evans, E., \& Gray, E. (2011). Living-apart-together (LAT) relationships in Australia. Family Matters, 87, 43-55.

Roseneil, S. (2006). On not living with a partner: Unpicking coupledom and cohabitation. Sociological Research Online, 11, 1-24. Retrieved from http://www.socresonline.org.uk/11/3/roseneil.html

Schenk, N., \& Dykstra, P. A. (2012). Continuity and change in intergenerational family relationships: An examination of shifts in relationship type over a three-year period. Advances in Life Course
Research, 17, 121-132. https://doi.org/10.1016/j .alcr.2012.01.004

Schutz, A. (1972). The phenomenology of the social world. Portsmouth, NH: Heinemann.

Setttersten, R. A., Jr. (2003). Propositions and controversies in life-course scholarship. In R. A. Settersten Jr. (Ed.), Invitation to the life course: Toward new understandings of later life (pp. 15-45). Amityville, NY: Baywood.

Stephure, R. J., Boon, S. D., MacKinnon, S. L., \& Deveau, V. L. (2009). Internet initiated relationships: Associations between age and involvement in online dating. Journal of Commuter-Mediated Communication, 14, 658-681. https://doi.org/10. 1111/j.1083-6101.2009.01457.x

Stevens, N. (2004). Re-engaging: New partnerships in late-life widowhood. In K. Davidson \& G. Fennell (Eds.), Intimacy in later life (pp. 47-64). London, UK: Transaction Publishers.

Stoilova, M., Roseneil, S., Carter, J., Duncan, S., \& Phillips, M. (2017). Constructions, reconstructions and deconstructions of "family" amongst people who live apart together (LATs). The British Journal of Sociology, 68, 78-96. https://doi.org/10. 1111/1468-4446.12220

Stoilova, M., Roseneil, S., Crowhurst, I., \& Santos, A. C. (2014). Living apart relationships in contemporary Europe: Accounts of togetherness and apartness. Sociology, 48, 1075-1091. https://doi.org/10 $.1177 / 0038038514523697$

Strohm, C. Q., Seltzer, J. A., Cochran, S. D., \& Mays, V. M. (2009). Living apart together relationships in the United States. Demographic Research, 13, 177-214. https://doi.org/10.4054/DemRes.2009. 21.7

Talbott, M. M. (1998). Older women's attitudes towards men and remarriage. Journal of Aging Studies, 12, 429-449. https://doi.org/10.1016/ S0890-4065(98)90028-7

Turcotte, M. (2013). Living apart together. Ottawa: Statistics Canada.

Upton-Davis, K. (2012). Living apart together relationships (LAT): Severing intimacy from obligation. Gender Issues, 29, 25-38. https://doi.org/10 .1007/s12147-012-9110-2

Upton-Davis, K. (2015). Subverting gendered norms of cohabitation: Living apart together for women over 45. Journal of Gender Studies, 24, 104-116. https://doi.org/10.1080/09589236.2013.861346

Watson, W. K., \& Stelle, C. (2011). Dating for older women: Experiences and meaning of dating in later life. Journal of Women \& Aging, 23, 263-275. https://doi.org/10.1080/08952841.2011.587732

Yodanis, C., \& Lauer, S. (2014). Is marriage individualized? What couples actually do. Journal of Family Theory \& Review, 6, 184-197. https://doi.org/ $10.1111 /$ jftr. 12038 